\section{AMBIENTAÇÃO DE BASE HISTÓRICA Uma Expressão de Marketing}

Mário Jorge Pires'

Mylene (yrino Basso'

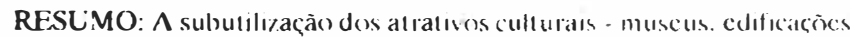
históricas. monumentes cte. normalmente encontlat sua justificialtuvil nat

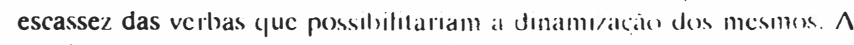
ambientação de basc histórica conslitui uma lértancinta. mtegrada an marketing cultural. que pode trazer grandes vantagens ao pattumo nio histórico $\mathrm{c}$ às compresas patrocinadoras. () prescintc artuge cslorca alguns aspectos dessa estratcy ara. pouco usadia no l brastl. mas hem suce dida na Europa c nos I stados Enidos.

PALAVRAS-CHAVI: Turismo c lazcr: marketung culturat: património histórico. Turismo cultural. I a/cr cultural.

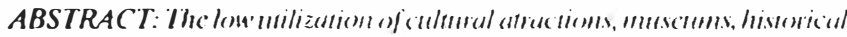

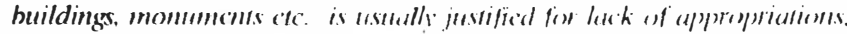

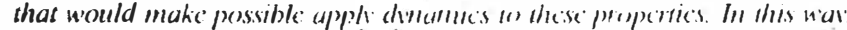

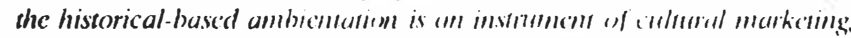

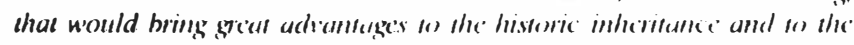

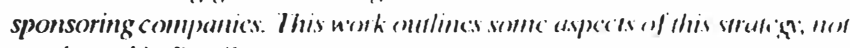
much used in Brazil.

KEY WORDS: Tourism and leisure: cultural markcting: historic inheritance. Cultural tomisism. (ulturul lisisure

\section{INTRODUÇÃO)}

Embora comumente considerado como perlencente au lerciário, 0 turismo está cntrelaçado com lodos os scelores da coconomia. Muildus das

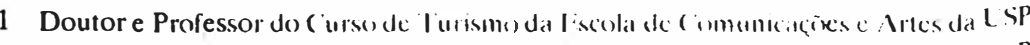

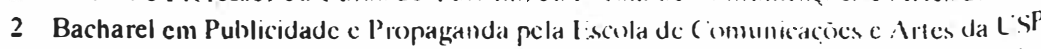

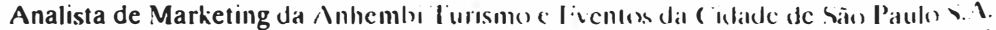

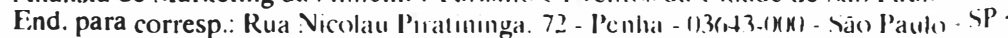
Brasil. sans atividades tendem a obcelecer às leis de mercado, nāo obstante distorçōes que na rcalidade podem ocorrer, como a formação de oligopolios e outras formas viciadas, às veces comuns não apenas cm turismo, mas também nas demais árćas.

Em condiçōes relativamente normais, a concorrência se processa nåo apenas entre as empresas prestadoras de scrviços (I ransportcs, hospedo apem, alimentação elc.), mas também entre as destinaçóes ( paíscs, cedades e atraçōes dentro da mesma localidade), provocando, desta maneira, a incessante comparaçào ent rc os produtos turísticos ${ }^{3}$.

Dentro de uma estratégia de markeling estabclccida, o objetivo essencial de qualquer produto é captar a maior fatia de mcrcado possivel. Para isso, no entanto, é neccssária a valorizaçāo máxima dos atrativos das destinações, de forma a proporcionar alıcrnalivas para os difercentes segmentos de público c incrementar um prolongamento da cstada nas mesmas. A ambientação de basc histórica pode, então, apresentar um elemento a mais para a valorizaçāo do parrimónio histónico, parte integrante dos atrativos turísticos.

\section{SUBUTILIZAÇĀO DOS ATRATIV(SS CULTURAIS}

No Brasil, a ênfasc dada aos recursos naturais das destinaçiocs especialmente após o advento dos modismos cecológicos - ¿́ quase cxclusiva, tornando ainda mais patentc a subutilizaçäo dos atrativos culturais, especialmente os ligados ao pat rimônio histórico.

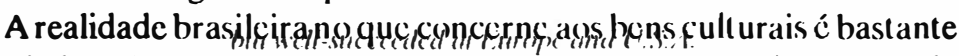
denunciada pela imprensa, uma ve\% que os remanescentes hislóricis da cultura material sequer recebem dos organismos públicos a devida preservação e conservaçào. ()s poucos existentcis que obtiveram alguma atenção apresentam um aproveitamento lurístico incipientc. É comum o visitante chegar a um bem histórico arquitctônico c apenas sc limitar à simples admiração passiva. Quando muito, sảo rcalizadas visitas monitoradas, freqüentemente enfadonhas em suas explanaçōes, scmpre iguais, independentementc do perfil dos frequéntadores. Pouquíssimos esforços foram feitos até agora cm se levantar as caractcrísticas dessa demanda e adequar as visitas a seus intcresses cspecíficos.

\footnotetext{
3

Adota-se aqui a definiçāo de Phılip Kotler. yuc considera produlu "qualquer coisa que possa ser oferecida a alguém para satisfazer uma nccessidade ou descio. abrangendo

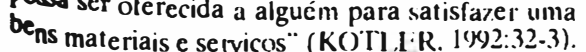


Os visitantes amcricanos e europcus, devem estranhar of fato tào comum de não tercm os muscus brasilciros, salvo algumas exceçōes, oferta de materiais ilustrativos, explicativos ou simples lembranças. Citase o caso do Museu de Arte Sacra, em São Paulo, onde nāo se pode entrar com câmara fotográfica - o que é regra na maior parte do primciro mundo mas também não há "slides" à venda c, até bem pouco tempo, nem mesmo cartōes postais.

Não só nos muscus, como cm outras edificaçōes históricas públicas, inexistem estratégias organizadas de forma a maximizar suas vantagens competitivas do ponto de vista do marketing. Como atraçōes nāo recebem um tratamento que as realce, provocando, assim, um verdadeiro desperdício dos já parcos recursos a elas destinados.

Nesse sentido, a ambientação de base histórica surge como uma ferramenta que permite uma mudança no enfoque tradicionalmente dado ao patrimônio histórico, buscando ut ilizaçōes mais voltadas às neccssidades e desejos dos visitantes

\section{AMBIENTAÇÃO) E AMBIENTAÇÃO HIST(ÓRICA}

Mas o que é ambientoçāo?

- Não permitindo uma definiçáo precisa, pode-sc dizer que sua principal característica prende-se à criaçāo de uma atmosfera especifica, proporcionando ao visitantc um cscapc à rotina cotidiana, através de experiências nāo vivenciáveis no dia-a-dia.

A ambientação pura e simples já vem sendo usada como estralćgia de marketing por alguns prestadores de serviço. (crtos restaurantes em São Paulo criaram atmosferas de abadia, convento ou tenda áralic. Igualmente conhecidos são os hotćis que trabalham com cstcrétipo de "Ilha da Fantasia".

A ambientaçāo de base histórica distingue-sc por utilizar-se dos recursos da ambicntação - cenografia, vestuário, iluminação, música, alimentação, dramatização ctc - para o aprovcitamento de bens históricos arquitctônicos, visando criar uma atmosfera consoante com a época c/ou representatividade que distinguiram essas edificações, a ponto de justificar sua prescrvação c conscrvação.

\footnotetext{
4 Enquanto se define presen'açùo como uma inte ıvenção lcgal c o rcconhecimento oficial de um bem histórico. conscriaçăon é uma intervenção física "para asscgurar sua integridade estrutural e estética" (FITCH. 1981:37)
}

A ambientaçāo de base histórica nāo sc confunde necessariamente com o mero teatro, que também pode acontecer dentro do bem histórico.

Em

máỏmo o envolvimento do visitantc, atravćs da participação ativa. Também nãoé obrigatoriamente uma reprodução didát ica da época abordada - pois esta, em alguns casos, poderia representar um desastre do ponto de vista do marketing - mas um recorte no tempo capaz de criar uma identificação emocional no visitante ${ }^{5}$.

Este recurso, usado de forma tão incipiente no Brasil, já é largamente empregado como estratégia de marketing turístico na Europa e nos Estados Unidos. Bastante conhecida c divulgada é a realização de bailes, jantares e torneios - estes últimos imitando lutas medicvais - em castelos, especialmentc na França e Inglaterra, utilizando música ao vivo em instrumentos de ćpoca, vestimentas, às vezes também usadas pelos turistas, iluminação, pratos típicos c rituais. Nos Estados Unidos, no chamado "triângulo histórico", comprecndendo as cidades de Williamsburg, James Citye Yorkıown, na Virgínia, a reconstruçāo chega a detalhes impressionantes. Em menos de meia hora de automóvel, o visitante pode vivenciar intensamente a experiência dos colonizadores nortc-americanos dos séculos XVII e XVIII. Nas casas preservadas ou reconstruídas e mobiliadas com peças originais ou com boas reproduçōes, funcionam diversos serviços da ćpoca, como fcrreiros, sapatciros, impressores, cabeleireiros etc., trabalhando propositalmente com ferramentas e tćcnicas do século XVIII, devidamente caractcrizados cm suas vestimentas. Armazens restaurados reproduzem o mercado colonial c comcrcializam objetos artesanais em porcelana, cstanho e ferro fundido, tabaco, ervas, cestas, chapéus e livros de cozinha com reccitas do período colonial. Os restaurantes servem pratos típicos e atć uma aldcia indígena foi reconstituída com atores (FRANÇA, 1992).

No Brasil, pode-se considerar como um tipo de (mmbientaçāo de base histórica - ainda que ocorrendo de forma cspontânca c não como estratégia de marketing - a Semana Santa em () uro Preto(M( $i$ ), onde o casario colonial serve de cenário às liturgias dos séculos XVIII c XIX, onde se utilizam paramentos, músicas c rituais da época.

5 Recriaģào histórica - geralmentc utilizada pela grandc imprensa - cnçuadrar-sc-ia como uma expressāo mais abrangentc. englolando até mesmo a reconstruçāo de edificicaçðes. expediente relativamente comum nos chamados "muscus ao ar livre".
Mais específica, a ambicntaçào de base histérica pode ocorrer. por excmplo. no interior Mais específica, a ambicntaçào de basc histérica pode ocorrer. por excmplo. no interior
de uma edificação histórica pertencente a um "muscu ao ar livre". Sobrc csse assunto, de uma edificaçăo histórica pertencente a um "muscu ao ar livre". Solre csse assunto,
consultar NOUVEAUX... (1977). 
A ambientaçāo de base histórica nāo deve ser encarada apenas como mais um atrativo turístico, mas como um elemento que pode ser decisivo na estratégia mercadológica da destinaçào. Inicialmenté, ć visível o con traste entre as reaçōes do público a uma simples visila moniloradia c a bens históricos que contêm recursos de ambientaçào. Vale lèmbrar que, enquanto os hotéis de ()uro Preto ficam lotados durante a Sémana Santa a maioria das visitas monitoradas a muscus como o Pátio do Colćgio, cm São Paulo, é organizada por cscolas, sem caráter espontâneo. A mera descrição didática não encontra clos de ligação com a necessidade de estímulos emocionais c fuga do cotidiano, que as pessoas procuram no turismo, criando um distanciamento, mesmo para a pequena parcela do público interessada em lazer cultural.

Deve-se lembrar o objetivo fundamental do marketing, ou seja, "determinar as necessidades é descjos dos mercados-alvo c satisfazè-los mais eficaz e eficientemente que os concorrentes"(K()TLER, 1991:46) Atualmente, lograr esse objetivo encontra diversas dificuldades proporcionadas por características lípicas dos anos 90 , como o crescimento mais lento do mercado em relação às décadas passadas, a intensificaçào da concorrência local e internacional, a maior prolifcraçào de produlos e redução do seu ciclo de vida, a sofisticação do consumidor - que se torna mais exigente, bem informado e percebc mais as características análogas dos produtos, a maior sensibilidade dos clientes a preços e pressāo para seu rebaixamento, clevaçāo dos custos de propaganda c promoçào, ataque da concorrência a segmentos específicos de mercado c outros problemas relacionados à distribuição c força de vendas (K()TLER, 1992).

Mais do que nunca, os produtos - inclusive turísticos - devem explorar todas as características que possam diferenciá-los positivamente da concorrência e procurar nāo apenas satislàcr o cliente, mas "encantá-lo", torná-lo fiel; conquistar não apenas a sua lembrança cm rclação ao produto "share of mind", mas uma "participaçào cmocional" "share of heart", que leva à preferência sobre os concorrentes. Sempre é mais dispendioso conquistar novos clientes que manter a fidelidade dos ja existentes através da boa prestação de scrviços (K()TLER, 19)2).

No caso do turismo, mesmo que o cliente jamais volte a uma mesma destinação, a fidelidade ao produto tradur-se pela boa impressāo cau sada pela viagem e serviços usufruidos no seu decorrer, tornando-se o próprio visitante propagador de suas vantagens, o que é mais cficiente que qualquer outro tipo de propaganda.

Em última instância, o turismo atende a necessidade do cliente de viver algo diferente e prazciroso, pois o produto vendido é "um sonho, uma ilusão". A ambientaçāo de base histórica faz com que os bens arqui- de ser meros cenários da destinaçào turística para tetônicos deixe integrante desse sonho, trabalhando com um dos estereótorná-los parte indidos na cultura ocidental: a idéia de entrar na máquina tipos mais difundidos na cultura ocidental. a idcia de cntrar na máquina do tempo. As obras de arte e a comunicaçáa de masia requentemente abordam o passado, scja através da criaçāo de histórias que ocorrem abordamente em épocas anteriores, scja através da transposição de personagens atuai.

quadrinhos, novelas, seriados de televisão, desenhos animados etc.

Assim oferece-se ao visitante a possibilidade de complementar sua viagem no espaço, com uma quase autêntica viagem no tempo, onde o bem histórico arquitetônico dá o toque de realidade à representação, sendo o vistante parte e nāo mero expectador.

Algumas premissas são nccessárias, porém, para a utilização deste recurso na estratégia de marketing de uma destinação turística. Além do planejamento cuidadoso, é fundamental que os eventos assumam uma regularidade e previsibilidade que possibilitem sua inclusāo em calendários oficiais e divulgação através da mídia, de forma a garantir a demanda. As ações isoladas rapidamente cairão no esquecimento e significarão perda de investimentos.

\section{A EMPRESA SAI GANHANDO}

Como a grande parcela dos bens arquitetônicos que se prestariam a um trabalho de ambientaçāo histórica pertencem ou são administrados pelo poder público, a falta de verbas poderá ser alcgada como empecilho à aplicação da estratćgia. Nesse caso, a solução deve ser a busca de parceria com a iniciativa privada.

São comuns os casos de patrocínio de espetáculos musicais, teatrais exposiçôes de arte por grandes empresas, mesmo no Brasil. Muitas delas já reconhecem as vantagens de associar seu nome à cultura c agradar o público freqüentador de tais cventos. Essa prática ajuda a mclhorar a imagem da empresa perante a comunidade, uma vez que as artes sāo associadas à criatividade, desenvolvimento cult ural c aos melhores aspectos de determinada sociedade (FINN, 1992). Neste ponto, a ambientaçāo de base histórica aproxima-se muito dos eventos artísticos, se ć que não pode ser considerada como tal, na proporçāo em que se utiliza de diversas artes, além da história, para transmitir sua mensagem.

Os benefícios para as empresas que investem em eventos artísticos e culturais vão além das relações públicas com a comunidade. Scgundo uma pesquisa realizada pela Phillip Morris, intitulada $O$ Americano e as 
Artes ("American and the Arts"), o público que freqüenta esses eventos é "de alta renda, bom nívcl de instrução, possui imóvcis, gosta de viajar e freqüenta restaurantes. ()u seja, são os 'consumidores. idcais"'(FINN, 1992).

Ao patrocinar um cvento que utilizc a ambientıçāo de basc histónica, em um bem arquitetônico administrado pclo poder público, a empresa poderá realizar açōes promocionais que aproveitem o potencial desse público, tais como:

a) prática de merchandising: faixas, cartazcs, assinatura em folhetos explicativos e outros;

b) promoçāo de vendas: distribuição de brindes, degustação, cuponagem ${ }^{6}$ etc.;

c) comercialização de produtos de fabricação direta (filmes fotográgicos, alimentos e outros);

d) realização de pesquisa de mercado no local;

e) coleta de dados para composição de "mailing list".

Além dessas e outras promoçōcs no local, a cmpresa podcrá se beneficiar da propaganda do evento, incluindo divulgação oficial dirigida a turistas, além da cobertura da imprensa.

Outras formas complementarcs de viabilizar a ambientaçāo de base histórica nas edificaçōes públicas são a cobrança de ingressos c a venda de "souvenirs" que, além das simples lembranças, podem incluir livros, catálogos, baterias de slides c outros produtos culturais relacionadıs ao local e a sua história, scrvindo, assim, à difusão cultural.

Nos bens arquitetônicos pertencentes à iniciativa privada, a ambientaçāo de base histórica é um investimento que valoriza o local, proporcionando a tão desejada distinção $\mathrm{cm}$ rclação à concorrência, buscada para neutralizar a percepçāo "igualadora" dos consumidores em relação a produtos semelhantes. Podc-se citar aqui o cxemplo de um casarāo do II Reinado, em Valença(R.J), que realiza um chá impcrial: nelc os visitantes são servidos por "escravas", ao mesmo tempo cm que a "sinharinha" conta as histórias tradicionais que ccrcam a edificaçāo. ((iUEDES, 1992:10)

\section{s CONSIDERAÇÖES FINAIS}

Voltando à questão inicial, onde se afirmou o carátcr compctitivo das destinaçōes entre si, especialmente as brasilciras e as do cxterior, verifica-se que essas últimas já estāo trabalhando há muito tcmpo para verimizar seus recursos usando, inclusi

As destinaçōes turísticas brasileiras nao podem maıs acomodar-se na idéia de que seus recursos naturais priviligiados bastam para manter cativa a demanda. É neccssário utilizarcm-sc todas as "armas", valorizar ao máximo seus pontos positivos, pois, a curto prazo, os que podem escolher e gastar priorizarāo os produtos turísticos que mais vantagens oferecem, que melhor atendem seus desejos e necessidades.

Quanto aos inertes, tenderão a desaparecer ou a continuar se contentando com as migalhas da demanda, visitantes de perfil indefinido, que contribuirāo para

divulgar uma imagem negativa das destinaçōes, pelo fato delas não terem desenvolvido atrativos $\mathrm{cm}$ maior conformidade com as tendências de mercado.

\section{REFERENCLAS BIBLIOGRÁFICAS}

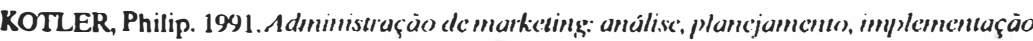
e controlc. 2 ed. Trad. dc Ailton Bonfin Brandão. São Paulo: Atlas.

FITCH, James M. 1981. Presen açóo do património argutitchônicon. São Paulo: FAU-USP.

NOUVEAUX aspects du musćc d' histoirc. 1977. Muscum!n. n. cspecial.

FRANÇA, Marth San Juan. 19)2. A vida era dura no icmpo das diligéncias. O tistado de Sáo Paulo. Sảo Paulo. 4 ago... p.). (Suplemento "Viagcm").

KOTLER, Philip. 1992. Total markcling: est ratćgias vencedoras dc markcting para os anos 90. SEMINÁRIO TO'IAI. M^RKE TIN(i. São Paulo: Anhcmbi Turismo c Eventos. (Palestra)

FINN, David. 1992. Artc-cinpresa: uma parccria multiplicadora. São Paulo: SESC-Paulista, 2 set. (Palestra)

GUEDES, Layla. 1992. Úma visifa ao $1 \mathrm{cmpo}$ dos harōes do cafć. ( ) Fistado de Süo Paulo, 8 set. (Suplemento "Viagem")

6 Entende-se por cuponagcm qualque rest ratćgia promocional quc envolva a distribuiçajo de cupons. Fistes podem ser recortados de anúncios imprcssos. distriluuídos ao $\mathrm{s}$ adquirir um produto ou en cuentos cspecíficos. Podem ser trocados por brindes. ingressos, utilizados em sorteios ou de outra forma imaginada pelo rcsponsável da promoção. 